\section{Laboratory Design for High-Performance Electron Microscopy}

\author{
Michael A. O'Keefe, John H. Turner \& John A. Musante \\ Lawence Berkeley National Laboratory, Berkeley, CA, USA \\ Crispin J.D. Hetherington* \& A.G. Cullis ${ }^{* *}$ \\ *Oxford University, and ${ }^{* *}$ The University of Sheffield, UK \\ Bridget Carragher, Ron Jenkins \& Julie Milgrim, \\ Ronald A. Milligan \& Clinton S. Potter \\ The Scripps Research Institute, La Jolla, CA, USA
}

Lawrence F. Allard, Douglas A. Blom,

Lynn Degenhardt \& William H. Sides

High Temperature Materials Laboratory, ORNL, Oak Ridge, TN USA

\section{Introduction}

Since publication of the classic text on the electron microscope laboratory by Anderson [1], the proliferation of microscopes with field emission guns, imaging filters and hardware spherical aberration correctors (giving higher spatial and energy resolution) has resulted in the need to construct special laboratories. As resolutions improve, transmission electron microscopes (TEMs) and scanning transmission electron microscopes (STEMs) become more sensitive to ambient conditions. State-of-the-art electron microscopes require state-of-the-art environments, and this means careful design and implementation of microscope sites, from the microscope room to the building that surrounds it. Laboratories have been constructed to house high-sensitive instruments with resolutions ranging down to sub-Ångström levels; we present the various design philosophies used for some of these laboratories and our experiences with them. Four facilities are described: the National Center for Electron Microscopy OAM Laboratory at LBNL; the FEGTEM Facility at the University of Sheffield; the Center for Integrative Molecular Biosciences at TSRI; and the Advanced Microscopy. Laboratory at ORNL.

\section{Factors}

The ultimate performance of the most sensitive electron microscope is strongly influenced by factors such as magnetic fields, vibrations, barometric pressure changes, both room and chilled-water temperature variations, and grounding problems. Vertical vibration of the specimen within the objective lens will contribute to the spread of focus in the image and can limit the attainable resolution. Horizontal vibration will smear out the image and limit resolution directly -- usually more in one particular direction. Vibration can reach the microscope through the floor (background vibration from vehicular traffic, heavy industry, natural microseisms or even microscope ancillary equipment) or through the air (acoustic vibration). Improper design of room cooling can buffet the microscope and act like vibration or lead to changes in temperature resulting in drift. Microscopes are most sensitive to low frequency vibration (in the range of a few Hertz) and these vibrations are the most difficult to eliminate from the microscope's environment.

Electromagnetic interference and stray magnetic fields can cause aberrations in the high-resolution TEM image, scanning distortions in STEM images and loss of energy resolution in EELS. Images and small probes can be blurred by AC field deflections in ways similar to the effects of vibration. Beams can be deflected from proper positioning at energy filter apertures, even by factors as simple as the movement of an operator's (metal) chair.

\section{8 mICROSCOPY TODnY May 2004}

Variations in air temperature cause drift -. of the specimen, of the microscope electronics, and of the mechanical tolerances in components including microscope lenses, correctors, and scan coils. Image reconstruction from focal series and elemental mapping with an imaging filter both require acquisition of multiple exposures of the same area of specimen; hence, specimen drift must be small over periods of several minutes, placing strict limits on room temperature variation. To avoid the temperature variations caused by cycling airconditioning, microscope rooms should be large (or there should be a large plenum of air in the HVAC system) and have only the minimum number of heat-producing sources. Similarly, changes in temperature of the chilled water can cause image drift effects. Barometric pressure changes or pressure changes caused by opening and closing laboratory doors also can affect sample holders that are exposed to the environment, such as typical side-entry stage rods. Finally, in laboratories where specimens must be transferred into cold stages and kept at liquid nitrogen temperatures, the humidity of the room must be kept low to avoid contamination by frost and ice.

\section{Designs and Implementations}

Electron microscope laboratories at our four institutions [2-4] have taken similar approaches designed to minimize adverse ambient conditions caused by the environmental effects described above (Fig. 1). Acoustic noise, vibrations and heat from electron microscope ancillary equipment are minimized by separating the equipment room (yellow) from the microscope room (green) with sound-and-vibration attenuating internal walls. Low-frequency vibrations coming through the laboratory foundations are minimized by mounting the microscope on a large heavy concrete pad (blue). Air-handling systems (HVAC) are designed to deliver just enough cold air to balance the heat production of the sources in the microscope room (including the operator) so as not to cycle between temperature extremes. The four laboratories were prepared for different circumstances. The NCEM's laboratory is a three-room extension to an existing building (Fig. 1a). Sheffield University's is a one-room site in an existing building (Fig. 1b). The TSRI (Fig. 1c) and ORNL labs (Fig. 1d) were built as new facilities, to house six and four microscopes respectively, with the TSRI lab optimized for biological use and the ORNL for high-resolution materials STEM/TEM.

\section{NCEM/LBNL:}

The National Center for Electron Microscopy's One-Angström Microscope (OAM) laboratory [2] was built in 1996 to house three high-resolution electron microscopes (Fig. la). The general seismic instability of the location in Northern California produces a constant background of small vibrations called microseisms. Since low-frequency $(<5 \mathrm{~Hz})$ vibrations are best attenuated by large masses, we mounted the microscope on a thick concrete isolation slab. Pumps and ancillary equipment such as chillers were banished to an adjacent equipment room behind a solid wall with acoustic damping on both sides. To de-couple the instrument room slab from the rest of the world, we specified an air-gap at the perimeter of the isolation slab. Cost, and the discovery of shallow bedrock on the site, limited us to a $3 \mathrm{ft}$-thick slab extended to occupy most of the microscope room area (about $1 \mathrm{~m}$ by $3.3 \mathrm{~m}$ by $4.2 \mathrm{~m}$ ) placed directly on a thin layer of compacted engineered fill (Fig. 2). Construction practicalities replaced the air-gap with a 1 "layer of closed-cell foam, with the advantage of preventing the accidental dropping of vibration-coupling objects (e.g. screwdrivers) into the gap.

Measurements of vibration spectra, carried out using a B\&K type 2515 vibration analyzer with an 8318 sensor, show significant 
attenuation of vibration on the slab (Fig 3). Vertically, vibration attenuation is close to a factor of three in the critical range from $1 \mathrm{~Hz}$ to $5 \mathrm{~Hz}$ (Fig.3 top); horizontal attenuation in this range is even stronger (Fig. 3 center and bottom). Our final layout moved the HT tank and computers to the back room to join the ancillary equipment. To move the computer noise and heat out of the instrument room we used solid-state amplifiers that allowed us to extend the keyboard, mouse, and monitor cables to $25 \mathrm{ft}$. Because the ground sloped sharply up to a road at the rear of the building, we built a retaining wall to create an air-gap separation between the back of the building and the hill. Offices, required for the second floor, all have carpet over thick rubber pad to mitigate foot fall impacts. Walls between instrument rooms and back rooms extend up to the base of the office floor to ensure acoustic separation.

All four walls in both the equipment room and the main microscope room were made acoustically "dead" by application of a $50 \mathrm{~mm}$-thick cloth-covered fiberglass sound absorbent. In the microscope room, air currents were minimized by arranging the air inlets along the side of the room farthest from the microscope column, providing a laminar flow down the wall and across the floor: Individual air-handling units were provided for each microscope room for temperature stability with variations of less than $0.5^{\circ} \mathrm{C}$ per hour. To minimize electromagnetic interference, all power conduits were routed as far as possible from the microscope column, giving a measured field of less than 0.1 milliGauss at $60 \mathrm{~Hz}$. Power and signal cables, and all cooling-water hoses, were routed between the rooms in cable trenches (Fig.la).

\section{University Of Sheffield:}

The electron microscope laboratory required a JEOL 2010F to be located in refitted accommodation in an eighty-five year old building in Sheffield [3]. To prepare the site for the microscope, we used a microscope foundation consisting of a large ( $1 \mathrm{~m}$ thick and $4 \mathrm{~m}$ square) concrete base weighing around $30,000 \mathrm{~kg}$, poured onto the sandstone bedrock and isolated from the building foundation with a $2 \mathrm{~cm}$ air gap. For comparison, the weight of the TEM is around $1,500 \mathrm{~kg}$. Precautionary measures were taken to reduce the entrance of noise and to damp noise in the room. Principal among these was to remove noisy microscope equipment (pumps, power racks, compressor) to a pur-

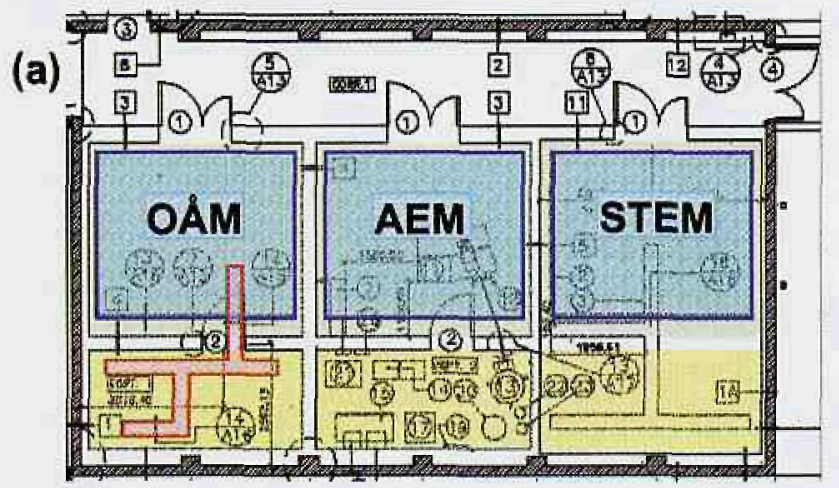

(b)
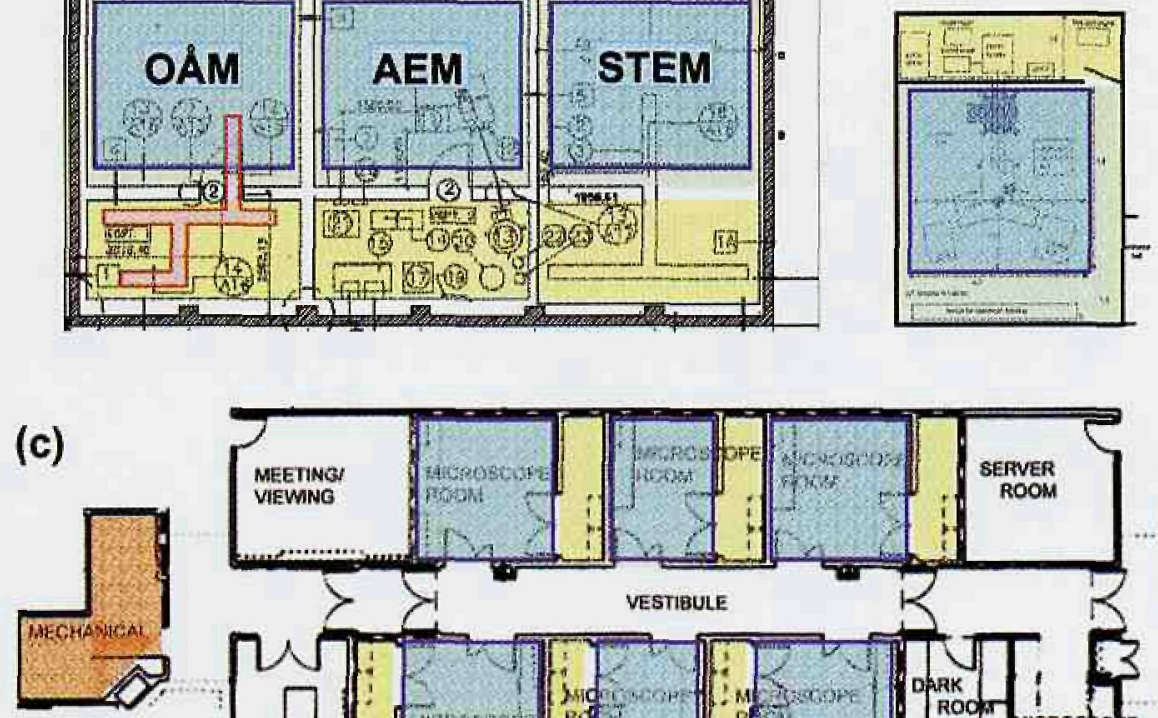

(d)
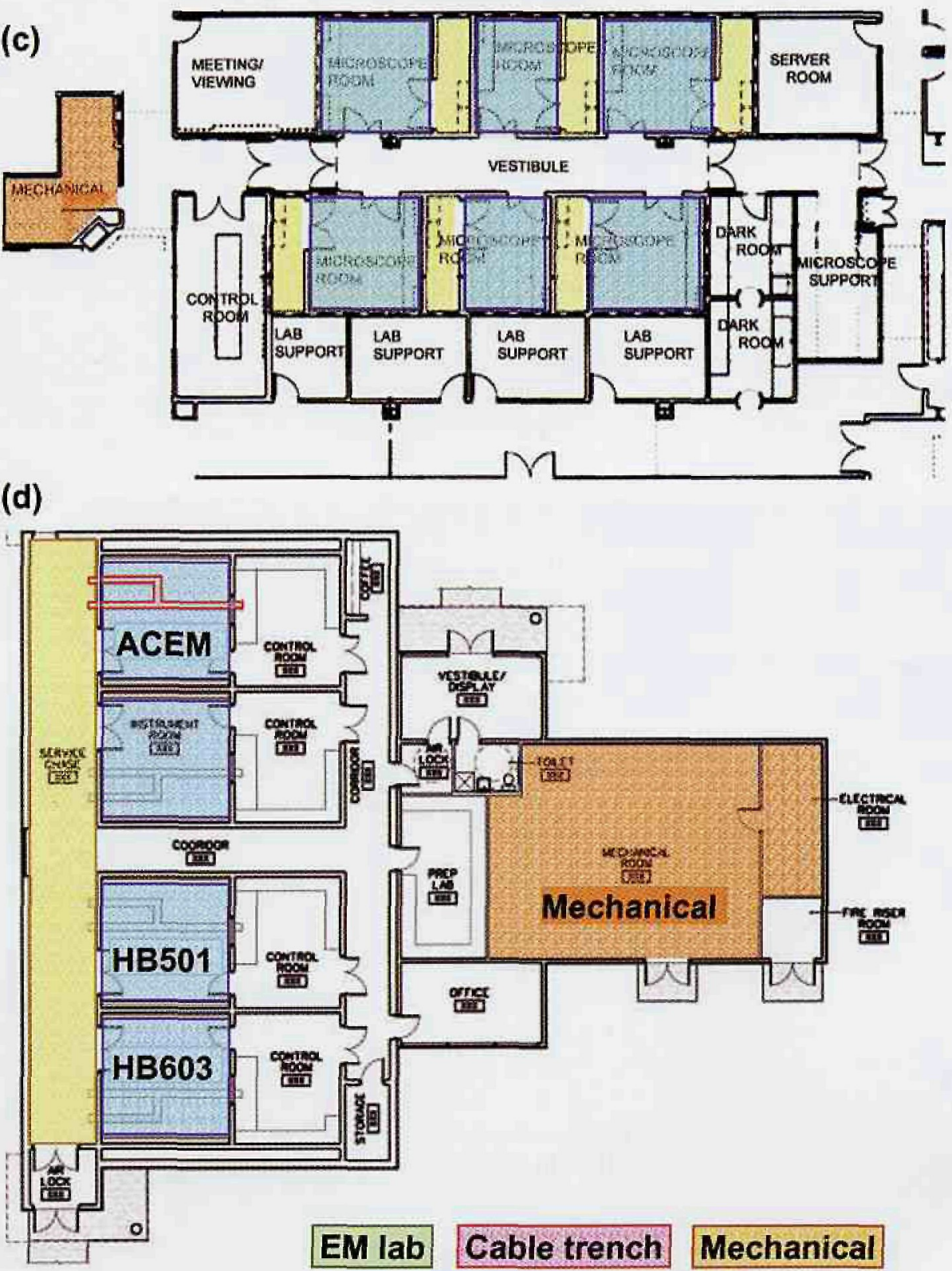

\section{Anti-vibration slab EM equipment}

Figure 1. Floor plans show the similarities and differences in the layouts of the facilities at LBNL (a), Sheffeld (b), TSRI (c) and ORNL (d). Colors show the instrument rooms (green) containing antivibration slabs (blue). The EM equipment areas (yellow) are connected to the instrument rooms via cable trenches (red) containing power and signal cables and cooling water lines. Mechanical and electrical areas (beige) are located at a distance. 


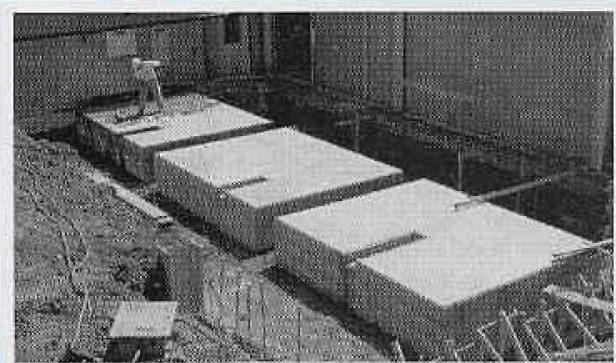

Figure 2. The instrument room antivibration slabs at LBNL. Each slab is $14 f$ by $10 f$ by $3 f$ thick and weighs an estimated 34 tons. Cable trenches lead to the back equipment rooms (not yet constructed in this view).

Figure 3. Comparison of vibrations measured on (left) and off (right) the OAM anti-vibration slab for frequencies from 1 to $100 \mathrm{~Hz}$ and velocities from $0.1 \mu \mathrm{m} / \mathrm{sec}$ to $10 \mathrm{~mm} /$ sec. For low frequencies, vertical vibration is reduced by a factor of three or more (top). Horizontal vibrations are reduced by ten times (middle and bottom).
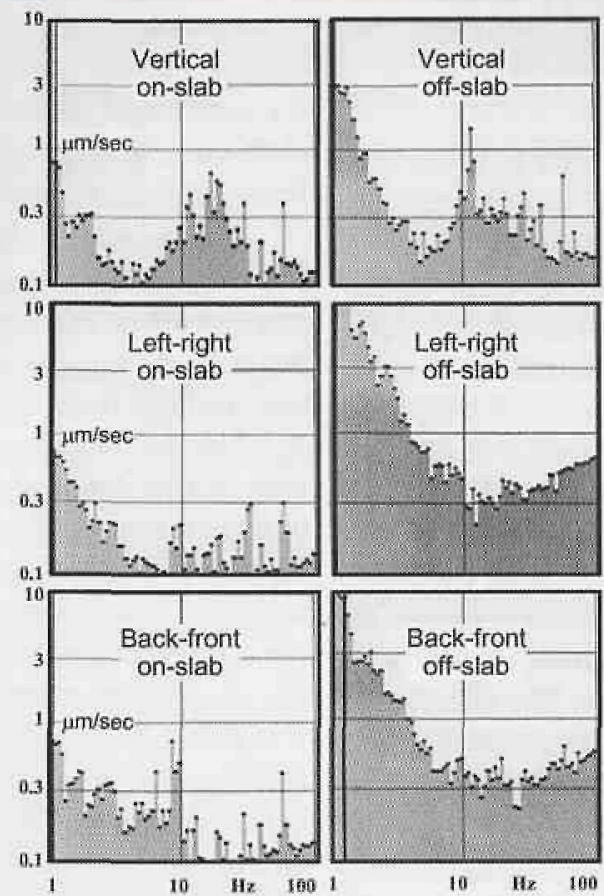

pose-built back room (Fig. 1b). A small entrance lobby was included, and the microscope room is therefore separated from a noisy corridor by two doors. A reduction of existing electro-magnetic fields at the Sheffield site occurred as a result of the general overhaul of existing wiring while installing the dedicated supplies for the microscope. The AC fields, once at an unacceptable $2.5 \mathrm{mGauss}$ ( $\mathrm{rms}$ ), are now less than the required $1 \mathrm{mGauss}$.

\section{TSRI/CIMBio:}

The focus of the Center for Integrative Molecular Biosciences is to study the structure of molecular machines and complexes through the use of integrative techniques including light microscopy, transmission electron microscopy, and X-ray crystallography. The Center is housed in a new building specifically designed to meet the needs of researchers. In particular the centerpiece of the first phase of development (completed in January 2002) is an electron microscopy suite [4].

Six microscope rooms are at the core of the suite situated on the ground floor (Fig. 1c). Auxiliary space includes darkrooms and a computer server room as well as support rooms for scanners, an optical diffractometer and other equipment. A control room center (Fig.4) provides computer and visualization facilities for monitoring experiments during data acquisition, as well as for data evaluation and analysis. Of the 6 microscope rooms, the 4 at the corners are each $13 \times 14$ ' and the middle two are slightly smaller at $10 \times 14$. Each microscope room has a separate equipment room at the rear that is $4 \times 14$ and is used to house support electronics, including the computers used to control the microscope and the CCD cameras. The floor of each microscope room consists of a large concrete pad, 3 ' thick, poured separately from the building slab on grade and then isolated by 2 " of styrofoam and a special isolation joint installed with the flooring. A sealer was sprayed over the concrete to help seal in the moisture. Rooms were constructed using full height steel stud with two layers of drywall installed on each side with a $1 / 2$ " resilient channel to provide a further sound cavity. In addition, tops and bottoms of the walls were caulked to the slabs to prevent transmission of sound and air. Before the first layer of drywall was installed, a layer of plastic was wrapped around the perimeter of the entire area. A second layer of plastic was installed at the ceiling and on the interior of each room to help prevent the migration of air between the dehumidified microscope rooms and the more humid common areas. Insulation was installed in every wall to help with the dampening of sound and vibration. On the interior of each room a layer of vinyl coated sound absorption board was installed after the drywall was complete.

Design considerations for the HVAC system include maintaining $<15 \%$ relative humidity for the entire suite, minimizing air movement within each microscope room and maintaining a constant temperature. The humidity requirement is designed to minimize frost and ice contamination during transfer of vitreous ice preserved specimens into cryostages and subsequent transfer of the cryostages into the microscope. A separate air handler serves the suite with a dedicated supply and return ductwork. Attached to that air handler is a desiccant drier. A "duct sox" was installed to the supply air inlet in each room to minimize air movement. The overall suite is separated from the outside environment by a set of double doors with pressure higher inside than outside to prevent the migration of non-humidified air into the suite. The chilled water required by each microscope is supplied by a chiller located in a separate mechanical room removed some distance from the suite (Fig. 1c), and travels by means of copper lines running to each individual equipment room. To minimize the effects of electrical interference and vibration, all electrical conduit, fire sprinkler mains, ductwork, chiller water lines, hot water lines, and drains were routed around the entire suite and only those lines serving the suite penetrated into the suite area. No electrical or water lines cross directly above any of the instruments. Network support for the suite includes Cat 5 connections to each microscope room. A cable tray runs from the server room along the vestibule to the control room. The control room features three $72^{\prime \prime} \times 54^{\prime \prime}$ projection screens and a custom built console. The microscopes are operated

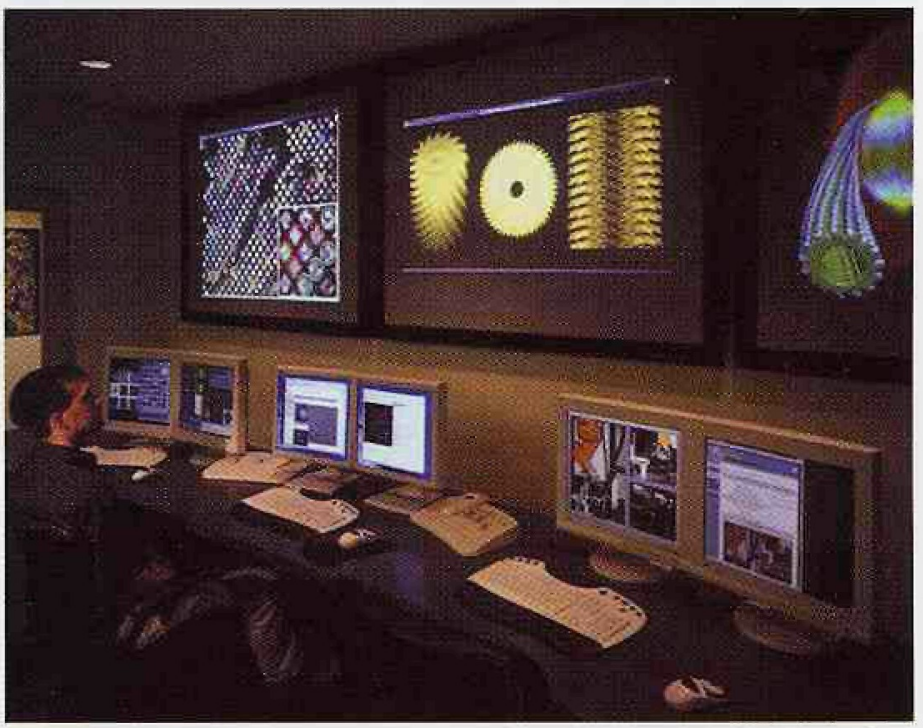

Figure 4. CIMBio microscope control room. Photograph courtesy of Hewitt/Garrison Architectural Photography. 
remotely from the control room, most commonly during automated data acquisition sessions (Fig. 4).

\section{ORNL/AML:}

The AML is a new microscope laboratory built to house four highly sensitive electron microscopes, including three aberrationcorrected instruments capable of sub-Angström imaging. It is able to be extended to twice its size to accommodate four more instruments in the near future. The floor plan (Fig 1d) shows how three of the microscopes, the aberration-corrected electron microscope (ACEM -- a JEOL 2200FS-AC with an aberration-corrected STEM probe), and the aberration-corrected VG Instruments (HB-501 and HB-603UX dedicated STEMs), are to be installed. The HB-603UX dedicated STEM has a design resolution of $0.5 \AA$ although its best has been $0.8 \AA$ in its present, less than ideal, environment. Instead of individual "back rooms" for each instrument, all ancillary equipment (with the exception of the water chillers) is housed in a common chase acoustically isolated from the instrument rooms. The microscope rooms are designed for instrument operation from control rooms that house the computers for remote control and additional facilities for data analysis.

Air movement is kept to the minimum. Entry to the building is through a vestibule and an airlock into the corridor that leads to the control rooms. Separate control of airflow and temperature in labs, control rooms and corridors is provided via individual hot-water-fed re-heat units for each area. An isolated mechanical building houses HVAC and instrument water chiller units, each supported on separate slabs. In the instrument rooms, air enters through a pair of large perforated supply ducts ( $50 \%$ open area) into a 5 -ft high volume above a porous acoustic drop ceiling, and exits at floor level into plenums on two side walls of each room (Fig. 5). The entire instrument room wall surface is covered by special acoustic/absorber blankets to effectively isolate the room from any noise (conversation etc.) that might be generated in an adjacent room. A single $4^{3} \times 4^{3}$

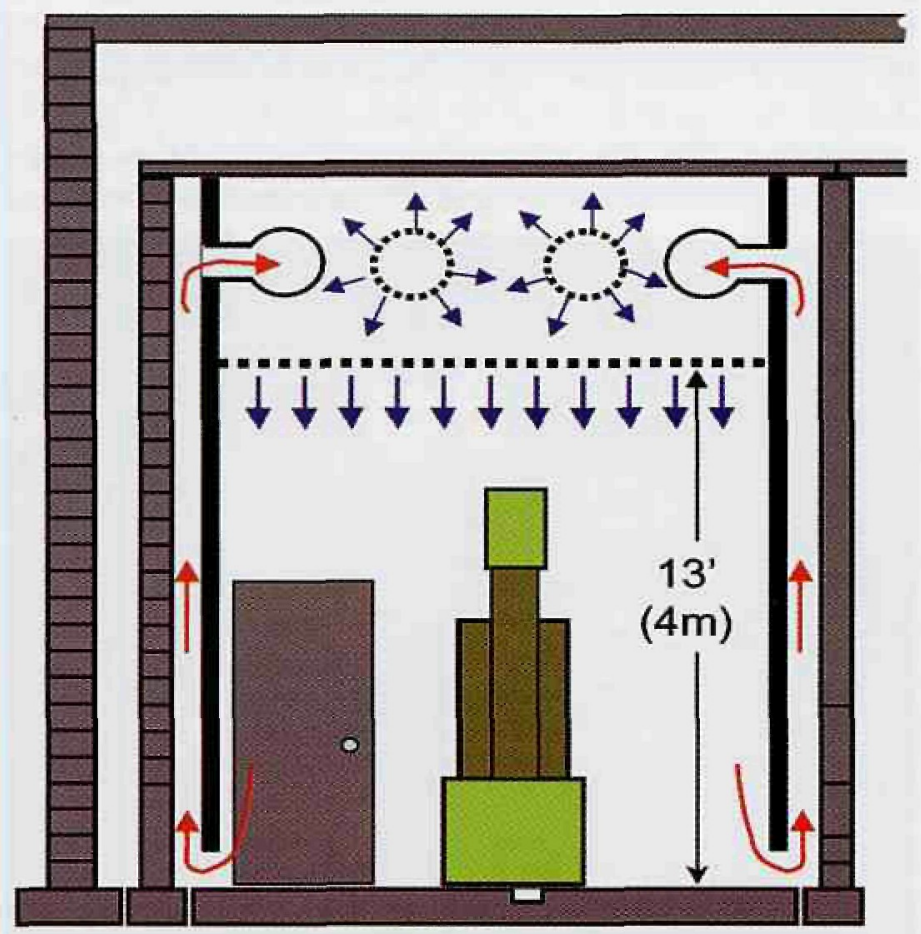

Figure 5. Cross section of an AML instrument room shows how cooling air is introduced above a porous ceiling and drops to the floor before being extracted through slots at floor level. window comprising a pair of double-paned windows (four panes in series for better sound isolation) was provided in the wall between the instrument and control room in each lab. Control rooms have cloth-covered acoustic absorber panels on each wall to absorb noise from conversation and computer fans.

The instrument building was constructed using a "house-inhouse" design philosophy, with a shell built from 12 " concrete blocks, and instrument and control rooms built using 8 " concrete blocks. The instrument room floor slabs ( 1 'thick, and the full area of the room) were isolated from the control rooms, corridors and service chase. The foundation slabs and wall footings were placed on a previously prepared site comprising several layers of "engineered fill" (to a depth of $8 \mathrm{feet}$ ) separated by layers of a "geotechnical fabric" material that together provide a stable, uniform base for the laboratory. This "slabon-grade" construction practice was deemed suitable, because the site is inherently very quiet, and similar construction in the adjacent HTML provides exceptionally low vibration levels.

Epoxy-coated re-bar tied together with plastic-coated wire was used to minimize the possibility of magnetic fields caused by currents in the foundation. Cost considerations dictated the use of a steel stud wall construction in the instrument building, but every attempt was made to assure (successfully to date) that no ground connections were made to the stud wall system, thus avoiding field generation in the structure of the instrument building. For the instruments, four separate ground systems were provided directly to the control rooms, each leading to triads of 10-foot long copper rods spaced 10-feet apart in soil near an adjacent small creek. To further mitigate the possibility of field generation by currents carried in other laboratory systems, dielectric de-coupling units were installed every 10 to 15 feet in all water lines, metal air ducts, compressed air lines and fire sprinkler piping. Twisted-pair wiring is used throughout both the instrument and mechanical buildings. Following the relocation of some external power lines that generated several milliGauss at the laboratory site, the microscope rooms are remarkably free of electromagnetic disturbances. Measured $60 \mathrm{~Hz}$ fields are less than 0.05 milliGauss.

Clean power is supplied to the AML from a 75kVA motor/ generator set housed in the adjacent HTML mechanical room (200 feet from the microscope suite). The MG set acts also as a UPS system, with battery backup provided for at least 5 minutes of operation after a power failure, sufficient for microscope safety systems to shut down, for example, field-emission electron gun operation. Chilled water for the HVAC systems and instrument water chillers is provided by the excess capacity available in the HTML, and compressed air is supplied from the HTML. Noisy pumps, compressors and especially the MG set, are thus totally isolated from the AML building.

\section{Other High-Performance Microscopy Laboratories:}

Like the AML described above, the Triebenberg Electron Holography Laboratory [5], $13 \mathrm{~km}$ east of Dresden, Germany was designed from the outset to minimize electromagnetic, mechanical, acoustic, and thermal disturbances to the electron microscopes. Power supplies, air conditioning, heating and cooling units, and other utilities are structurally isolated from the electron microscopes by placing them in a separate building with an independent foundation.

The SuperSTEM Laboratory at Daresbury [6] has been specially built to house two aberration-corrected STEMs. It has been designed to offer not just mechanical stability - low vibration - but low magnetic field levels and excellent temperature control. It includes separate electrical supplies, computer controlled air handling, close 


\section{THE T́NEXT GENERATION \\ I MA I ING IF I LTER HAS ARRIVED
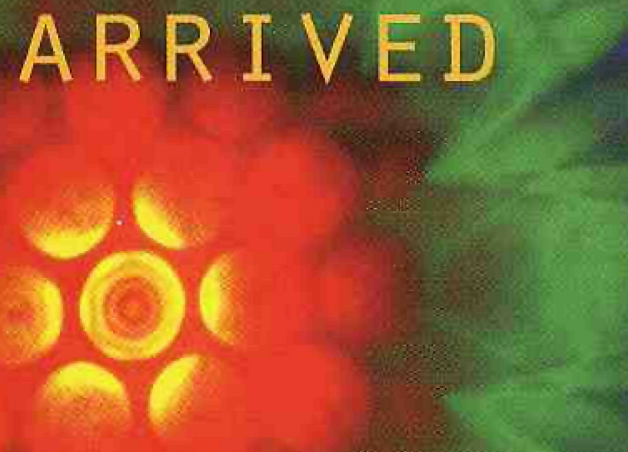

\section{PRECISION}
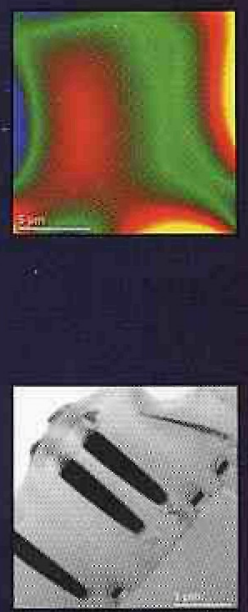

Gatan proudly announces GIF Tridiem, our Third Generation of post-column energy filters. GIF Tridiem combines $3^{\text {rd }}$-order spectrometer aberration correction with a multi-port, high-speed, high-resolution CCD sensor to yield a system that defines a new state-of-theart in the capture of highly-detailed

EELS and EFTEM data sets with maximum throughput. GIF Tridiem, combined with the Gatan Microscopy Suite (GMS) software, is ideally suited for generating and working with rich 3-dimensional data sets, including EFTEM and EELS STEM spectrum images, EFTEM tilt and tomography series, and time series. GIF Tridiem makes tri-dimensional EM readily accessible to the most demanding analytical electron microscopist.

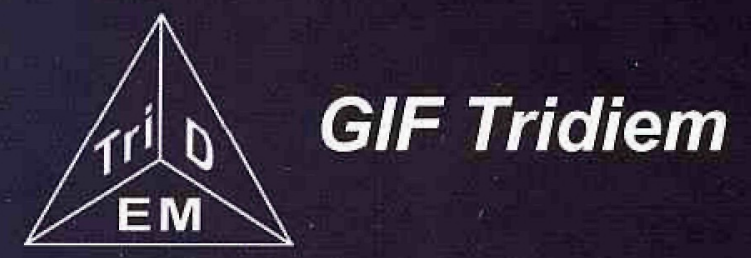

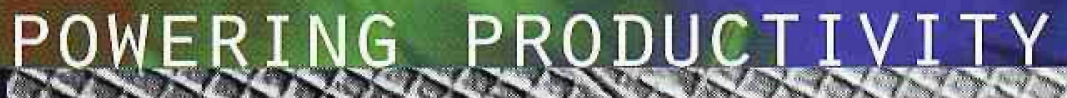

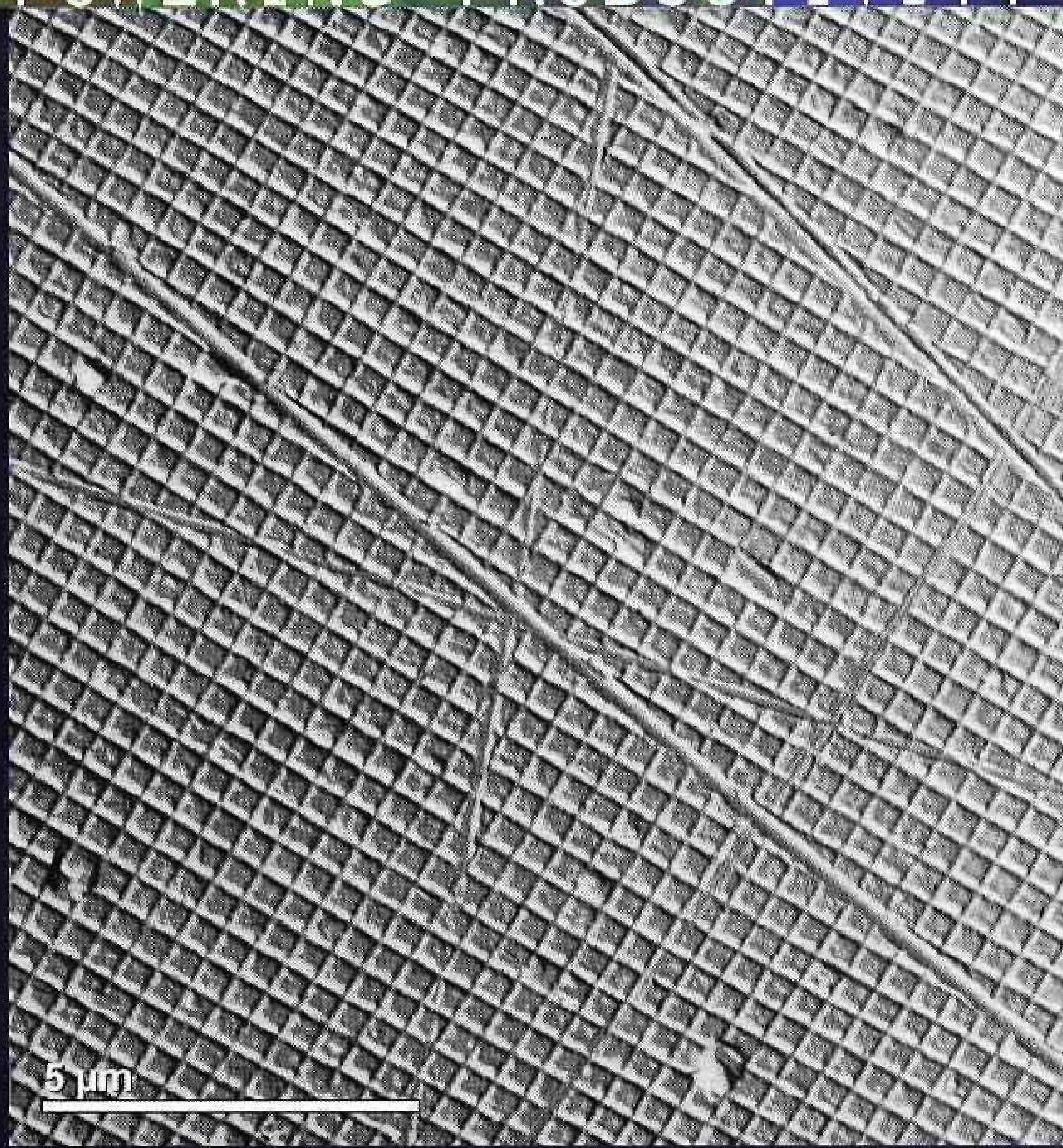

Left hand Imagas (hrom iop to bottom): (1) Energy devialion across

image field camreoted thru $3^{\text {rd }}$ order lo $<2 \mathrm{EV}$. (2) Unfittered

Bright-field TEM imsge of semiconductor device structure. (3) Calor

composite of elemental mans of semiconductor device structure.

Above imagos: (top) Zero-loss fitered CBED patlem of Si [U1] taken at $200 \mathrm{koV}$. FOLZ ing represents scattering angle of $78 \mathrm{mR}$.

(botion) Zero toss image of grating repplica showing large fieid of vilow for EFIEM. Grating piteh is $463 \mathrm{~nm}$.

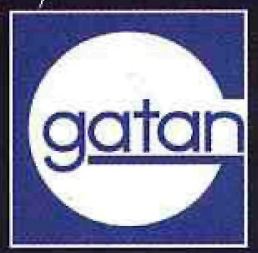


temperature control and air conditioning with long-term oscillation characteristics.

\section{Summary}

The problems to overcome are to ensure microscope stability by limiting vibration (background and equipment-generated), acoustic noise, changes in temperature, and alternating magnetic fields.

Our four labs (and the Triebenberg and SuperSTEM labs) all use heavy isolated foundation slabs for the instrument rooms, to attenuate background vibration. Generally these slabs are made as thick as possible ( $3 \mathrm{ft}$ or $1 \mathrm{~m}$ for LBNL, Sheffield, and TSRI; $2 \mathrm{~m}$ for Triebenberg). The AML requirement was met with a thinner $1 \mathrm{ft}$ slab based on experience with the quieter local ground conditions. To provide sufficient mass, slabs were sized to include most of the instrument room areas. Since an increase in the slab size is desirable, one slab for the whole building might appear best. However the diminishing returns of increased mass need to be balanced against the greater probability of additional vibrations. Any walls solidly anchored to the slab will act as antennae to couple-in acoustic vibration and lowfrequency vibrations produced by the wind moving over the building roof. One large slab could work if it were isolated from building walls (especially external walls), with the roof isolated from any walls coupled to the slab. Whatever route is chosen, vibration velocity on the microscope foundation should be kept below 1 micrometer per second in the critical 1 to $5 \mathrm{~Hz}$ frequency range (Fig. 3).

Acoustic noise in the instrument rooms is minimized by application of sound absorbing material on all four walls and the ceiling. Noise-producing equipment is relegated to a separate back room with a solid (absorbent-covered) wall between this room and the instrument room; for the TSRI and AML labs even the (noise-producing) operator can be removed to a separate control room. For the more-recent sites (TSRI, AML and Triebenberg), electrical power, chilled water and HVAC are supplied to the equipment rooms from a separate building. Large room volumes can allow the air conditioning to be switched off without significant temperature increase during noise-critical experiments (for 5 minutes at Triebenberg). With most heat-producing equipment removed to the equipment (back) room, air supply to the instrument room can be minimal and more easily controlled to avoid sudden temperature fluctuations. Lower airflow also provides the advantage of less chance of low-frequency (subsonic) "booming" in the supply ducts. Typical temperature fluctuations are kept to $0.1^{\circ} \mathrm{C}$ per hour (AML and Triebenberg) or $0.5^{\circ} \mathrm{C}$ per hour (LBNL, Sheffield and TSRI). Sudden pressure changes are avoided by the use of airlocks.

For high-resolution microscopes, $\mathrm{AC}$ magnetic fields are held to less than 0.2 to 1.0 milliGauss ( 20 to 100 nanoTesla) root-meansquare (rms). With careful design of power routing and isolation of transformers and electric motors, background fields (usually strongest at mains frequency) can be kept below 0.1 milliGauss. Use of flat-panel LCDs instead of CRT monitors removes an additional source of magnetic fields and heat production from the instrument room (often close to the microscope). Another precaution is the use of twisted-pair supply cabling. Purity of the supply waveform is improved by using remote motor-generator sets. Use of active compensation of fields may be necessary in some cases, although it should be kept in mind that current systems typically reduce the field only at the exact point of the single sensor. Also, in the case where microscope rooms are placed side by side, an active compensation system in one room may interfere with fields in adjacent rooms.
One potential problem is in interaction with architects and builders. These professionals are very good at supplying things they know about and can guarantee; but it can be difficult to get them to supply or build something with which they are unfamiliar. Good communication is essential to reduce the possibility of anyone making changes without discussion because they "know better" [7]. A scientific or technical liaison must always be able to keep a close eye on progress. Weekly progress and planning meetings are a good idea. Finally, it doesn't hurt to build the room (and the access doors) larger than you think you need; and install way too many power outlets.

\section{Conclusions}

The correct laboratory conditions are necessary for unfettered performance of current and future high-performance electron microscopes. The resolution of the CM300FEG-TuebingenSpecial improved from $1.2 \AA$ to $0.9 \AA$ when it was re-sited in the Triebenberg Laboratory [8]. The CM300FEG-OAM reached its designed $0.8 \AA$ resolution in the environment provided by the $O \AA M$ laboratory (see the companion article by O'Keefe $e t a l$. in this issue).

\section{Useful websites:}

LBNL/NCEM: http://ncem.lbl.gov/

Sheffield University FEGTEM: http://www.shef.ac.uk/eee/fegtem/ index.html

TSRI/CIMBio: http://cimbioscripps.edu/

ORNL/AML: http://www.ms.ornl.gov/htmlhome/mauc/aml.htm

Triebenberg Lab: http://www.physik.tu-dresden.de/iapd/ optics.php?lang=en

SuperSTEM: http://www.superstem.dl.ac.uk/indexj.html

\section{References}

1. "Design of the Electron Microscope Laboratory", R.H.Anderson. Volume 4 of Practical Methods in Electron Microscopy, edited by A.M. Glauert, North-Holland, Amsterdam, 1975.

2. "Design and Implementation of a Site for a One-Ångström TEM", John H. Turner, Michael A. O'Keefe and Robert Mueller, in 55th Ann. Proc. MSA, Cleveland, Ohio (1997) 1177-1178.

3. "Installing and operating FEGTEMs", C.J. Hetherington, A.G. Cullis, S. Walker, J. Turner, E.C. Nelson, and M.A. O'Keefe, Mat. Res. Soc. Symp. Proc. 523 (1998), ed. by C. Hayzelden, C.J.D. Hetherington, and F. Ross, 171-176.

4. "Design and Construction of a Suite for Molecular TEM", C.S. Potter B. Carragher, R. Jenkins, J. Milgrim and R.A. Milligan, Microscopy \& Microanalysis 9, supplement 2 (2003) 950-951.

5. "Electron Holography Lab Pushes Resolution Limit", March Issues and Events, Physics Today, March 2001, http://physicstoday.org/pt/vol-54/ iss-3/p24.html

6. "The SuperSTEM building", http://www.superstem.dl.ac.uk/web_ posters/build_13_l.png

7. At LBNL we specified sound absorbent on all four walls for maximum damping of acoustic noise generated in the instrument room. At a weekly meeting we found that they were installing it only on two walls because their acoustic expert had told them that any more would "make the room too dead to be comfortable".

8. "The Triebenberg laboratory -- designed for highest resolution electron microscopy and holography", Hannes Lichte, Dietrich Schulze, Michael Lehmann, Holger Just, Taher Erabi, Peter Fuerst, Jaqueline Goebel, Andreas Hasenpusch and Peter Dietz (2001) Microscopy \& Microanalysis 7, supplement 2, 894-895.

\section{Acknowledgements:}

The NCEM and work at LBNL are supported by the Director,Office of Science through the Office of Basic Energy Sciences, Matertal Sciences Division, of the U.S.Department of Energy, under contract No.DE-AC03-76SF00098. Planning and construction at ORNL provided by the Department of Energy, Office of Science Landlord General Plant Project funds for Oak Ridge National Laboratory, operated by UT-Battelle LLC under contract no.DE-AC05-000R22725.

TSRI supported by the National Institutes of Health though the National Center for Research Resources P4I program (RR17573). 


\section{LEO's New Microscopes Answer All Your EM Needs}

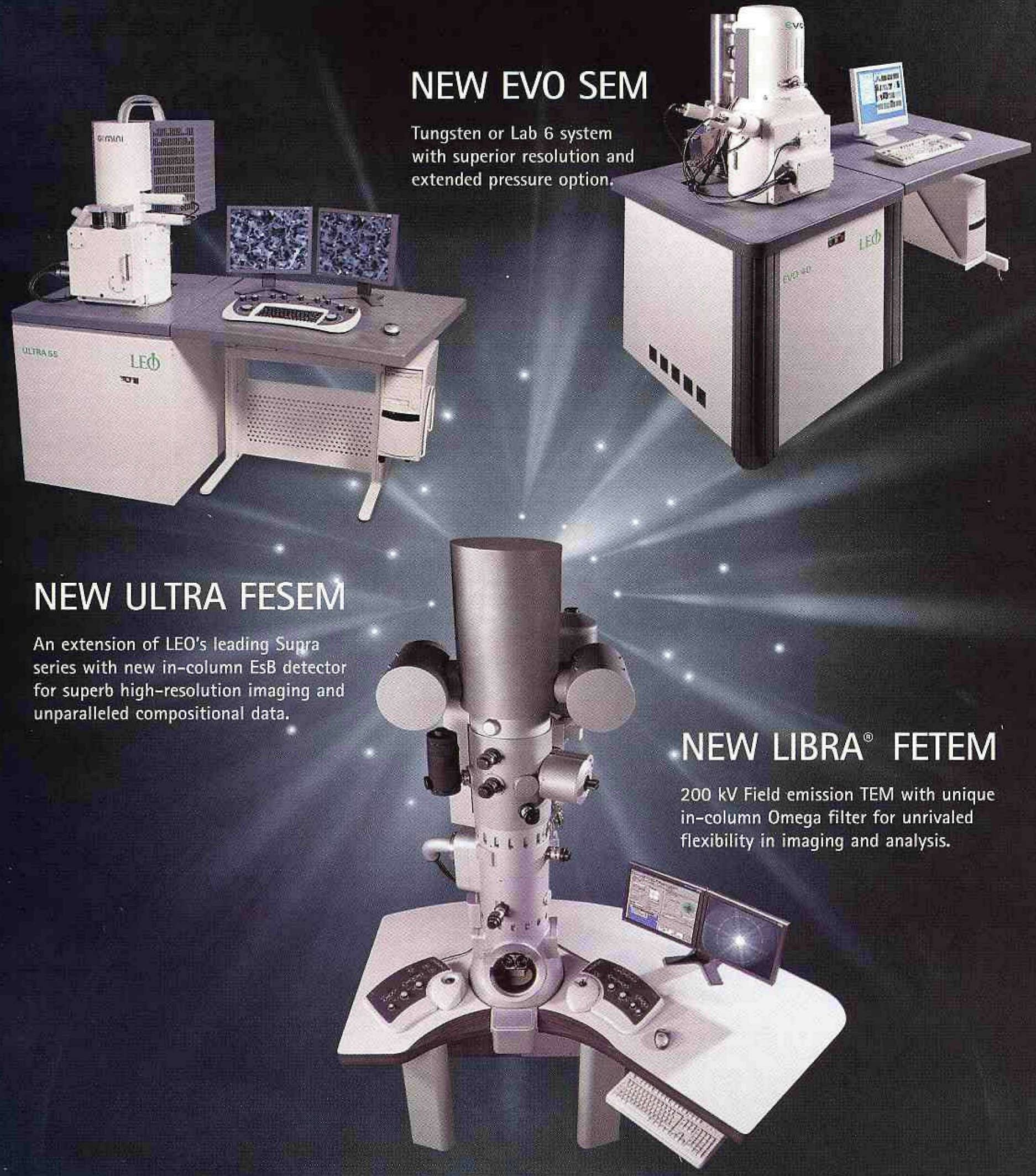

Enabling the nano-age world TM LO Electron Microscopy Group A Carl Zeiss SMT AG Company 73417 Oberkochen, Germany Tel: $++4973 \quad 64-946137$ Fax: ++497364944851 info@leode o wwwleo-em.com
LEO Electron Microscopy Inc A Carl Zeiss SMT AG Company Thornwood, New York 10594 Toll Free: $800-356-1090$ Fax: $914-681-7443$

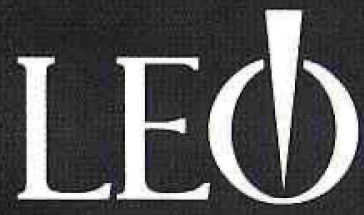




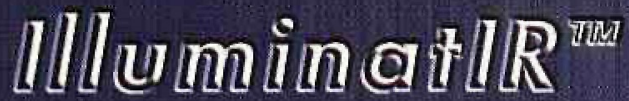

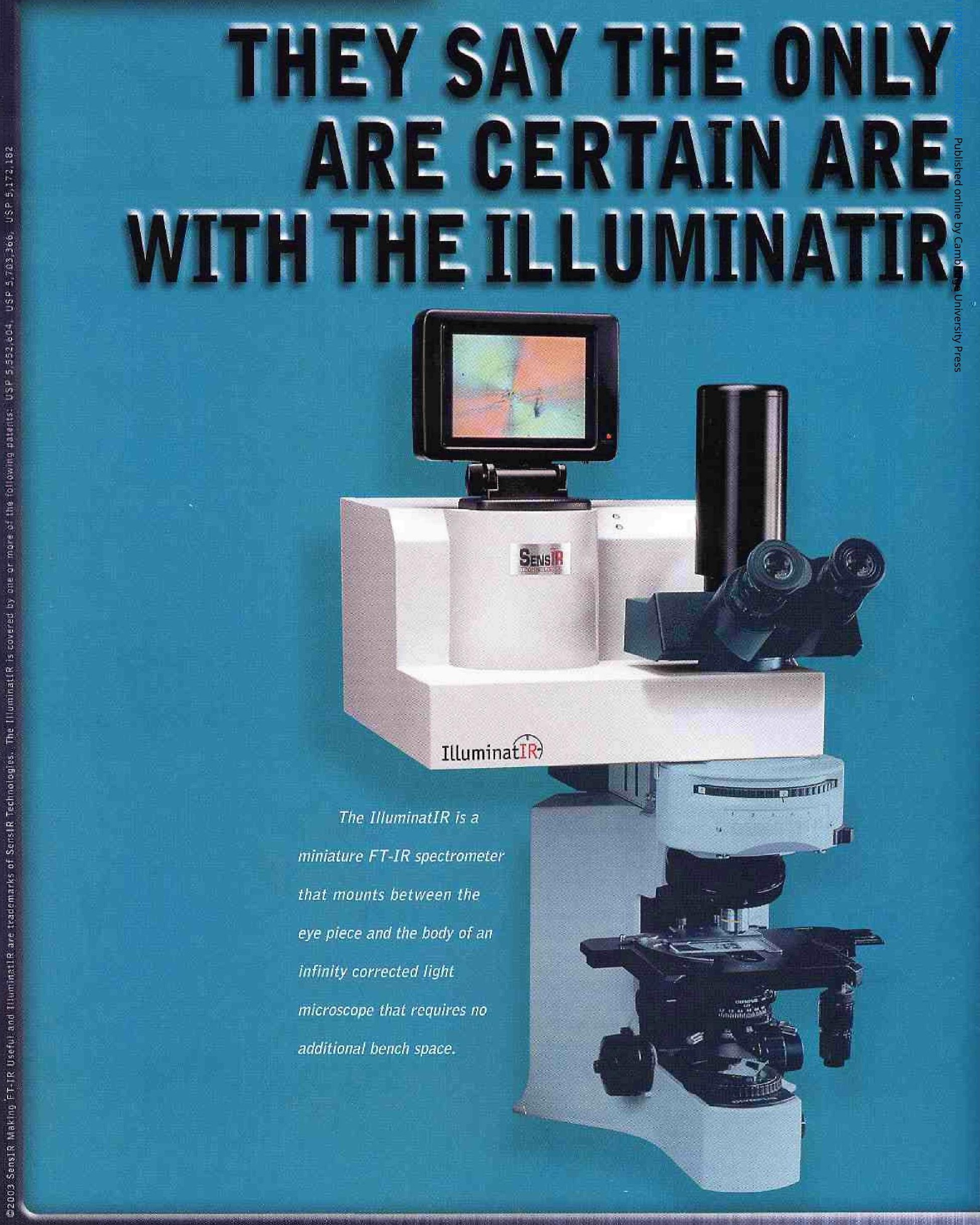




\section{THINGS IN LIFE THAT \\ DEATH AND TAXES,

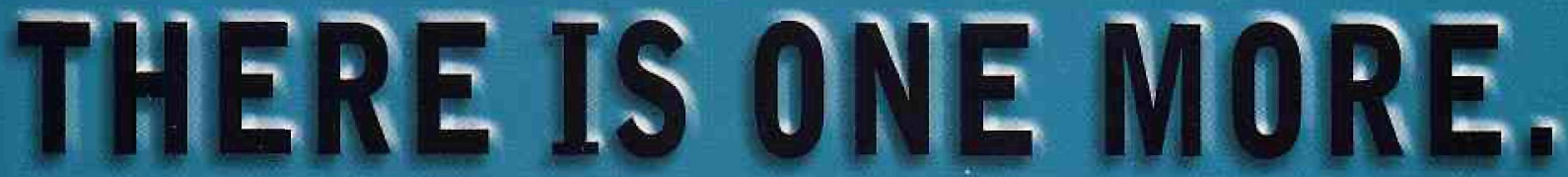

\section{IlluminatIR adds the power of FT-IR analysis to your light microscope}

Introducing the IlluminatIR, the only miniaturized FT-IR system that attaches directly to your favorite light microscope. Add the power of molecular analysis to your visual interpretation for the most accurate and objective results.
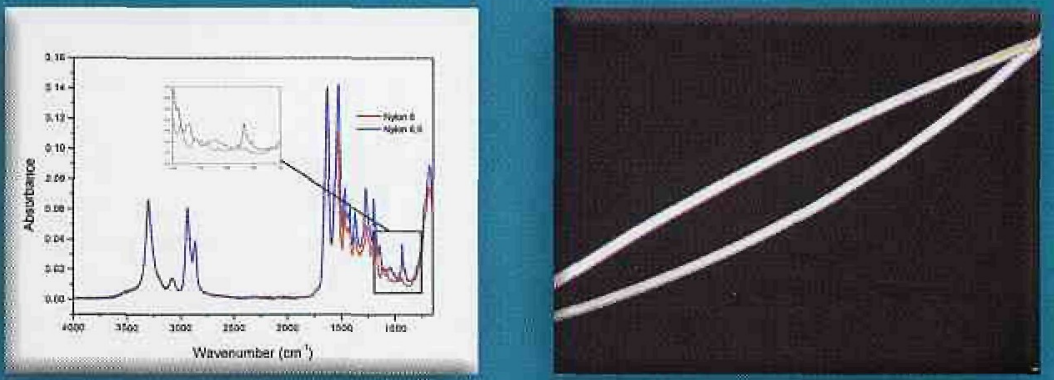

When samples are visually identical, FT-IR microscopy can show you the difference.

Wisually these two nwlon fibsers are identical. However when ET-IR analysis is run on onch of the fibers and their spetra is overlaid the difference in the two fibers bocomes clear. The top fiber was identified as Nylon 6 and the botiom fiber to be Nylon 6,6 .

Only IlluminatIR:

- provides high quality infrared data and superior visual quality

- easily attaches to infinity corrected microscopes

- maintains all the capabilities of your microscope,

i.e. polarization, fluorescence, Nomarski or image analysis, etc.

- can run FT-IR analysis simply with the turn of an objective - no need to move the sample

- adds these capabilities without taking up additional bench space

- very easy to use and maintain

The IlluminatIR: it will change the way microscopes are used forever.

\section{MAKE YOUR OWN OBJECTIVE OPINION.}

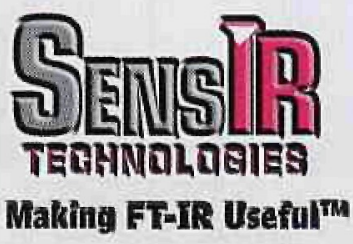

